\title{
Comparison of STI-related consultations among ethnic groups in the Netherlands: an epidemiologic study using electronic records from general practices
}

Petra J. Woestenberg ${ }^{1 *}$, Aloysia A. M. van Oeffelen ${ }^{1}$, Irina Stirbu-Wagner², Birgit H. B. van Benthem?', Jan E. A. M. van Bergen ${ }^{1,3,4}$ and Ingrid V. F. van den Broek ${ }^{1}$

\begin{abstract}
Background: Currently, surveillance of sexually transmitted infections (STIs) among ethnic minorities (EM) in the Netherlands is mainly performed using data from STI centers, while the general practitioner (GP) is the most important STI care provider. We determined the frequency of STI-related episodes at the general practice among $E M$, and compared this with the native Dutch population.

Methods: Electronic medical records from 15-to 60-year-old patients registered in a general practice network from 2002 to 2011 were linked to the population registry, to obtain (parental) country of birth. Using diagnoses and prescription codes, we investigated the number of STI-related episodes per 100,000 patient years by ethnicity. Logistic regression analyses (crude and adjusted for gender, age, and degree of urbanization) were performed for 2011 to investigate differences between EM and native Dutch.

Results: The reporting rate of STI-related episodes increased from 2004 to 2011 among all ethnic groups, and was higher among EM than among native Dutch, except for Turkish EM. After adjustment for gender, age, and degree of urbanization, the reporting rate in 2011 was higher among Surinamese [Odds Ratio (OR) 1.99, $95 \%$ confidence interval (Cl) 1.70-2.33], Antillean/Aruban (OR 2.48, 95 \% Cl 2.04-3.01), and Western EM (OR 1.24, $95 \%$ Cl 1.11-1.39) compared with native Dutch, whereas it was lower among Turkish EM (OR 0.48, 95 \% Cl 0.37-0.61). Women consulted the GP relatively more frequently regarding STls than men, except for Turkish and Moroccan women.

Conclusions: Most EM consult their GP more often for STI care than native Dutch. However, it remains unclear whether this covers the need of EM groups at higher STI risk. As a first point of contact for care, GPs can play an important role in reaching EM for (proactive) STI/HIV testing.
\end{abstract}

Keywords: Sexually transmitted infections (STI), STD, HIV, Testing, Ethnicity, General practice, Primary care

\section{Background}

In the Netherlands, sexually transmitted infection (STI) testing and care is mainly provided by general practitioners (GPs) and specialized STI centers [1-3]. In general, GPs are the core primary care providers in the Netherlands and function as a 'gatekeeper' to secondary health care. Nearly all Dutch inhabitants are registered

\footnotetext{
* Correspondence: Petra.Woestenberg@rivm.nl

${ }^{1}$ Centre for Infectious Disease Control, National Institute for Public Health and the Environment (RIVM), Bilthoven, The Netherlands

Full list of author information is available at the end of the article
}

at a general practice. Specialized STI centers provide additional low-threshold and free of charge STI care to certain high-risk groups [2, 4]. It is estimated that the annual number of STI-related consultation at the GP is over 300,000 , while there were about 120,000 consultations at the STI clinic in 2012 [2].

An important high-risk group eligible for free of charge STI testing at the STI centers are people originating from STI/HIV endemic areas (Turkey, Latin America (like Surinam, the Netherlands Antilles), Africa (like Morocco), eastern Europe, Asia) [2, 4]. As in other countries, certain

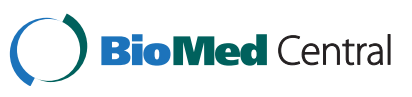


ethnic minorities (EM) are at higher risk to acquire STIs than the majority population, which is related to a higher STI prevalence in their country of origin, sexual networking or higher sexual risk behavior [5-10]. At the STI center, but also in other settings, people with a non-Dutch ethnicity are more often diagnosed with an STI than native Dutch. For example, in $201320.1 \%$ of the Surinam/ Antillean/Aruban EM, $18.3 \%$ of the Sub-Saharan African EM and $16.1 \%$ of the Moroccan/Turkish EM were diagnosed with an STI at the STI center compared to $13.9 \%$ of the native Dutch population. Also in a populationbased study, the chlamydia positivity rate was higher among Surinam/Antillean EM (8.2 \%) and Moroccan/ Turkish EM (3.1\%) than among native Dutch (1.8 \%) $[2,11-16]$. Therefore, it is important that EM are properly tested for STIs. This may not only reduce the risk of complications and improve the prognosis for the individual, but may also reduce transmission of STIs in the population.

Because the patients' ethnic background is not registered at the general practice, surveillance of STIs and STI testing among EM in the Netherlands is mainly performed using data from STI centers. However, the majority of the STIs is diagnosed at the GP, and most people with signs and symptoms suggestive of an STI consult their GP and not an STI center $[3,17,18]$. Although EM (originating from STI/HIV endemic areas) are indicated as high-risk groups for whom opportunistic STI-testing is recommended, it is currently unknown if these groups consult the GP for STI-related issues as frequently as native Dutch [19]. There are indications that EM consult the GP less frequently [20]. General practice surveillance data can give a broader insight in the frequency of STI consultations among EM in the general population and improve the surveillance of STIs [3, 21].

In the Dutch population registry, ethnic background of inhabitants is recorded by means of (parental) country of birth. By matching general practice data with data from the population registry, it became possible to determine the patients' ethnicity. Although a distinction based on ethnic background may be perceived as stigmatizing, it does provide more insight into primary care use among EM and it enables a more focused approach regarding service provision [22]. In this paper, we answered the research question: what are the differences in the number of GP consultations for STI-related issues between EM and native Dutch in the period 2002-2011?

\section{Methods}

\section{Data sources}

We used the Netherlands Institute for Health Sciences Research (NIVEL) Primary Care Database (NIVEL-PCD) to obtain the electronic medical records of participating general practices from 2002 to 2011. The number of general practices included in the NIVEL-PCD is dynamic and fluctuates from year to year (about 70 to 120 practices per year), but its composition is guarded so that the practices are representative of all Dutch general practices with regard to geographical distribution and degree of urbanization. The patients registered in these participating practices are also representative for the Dutch population with respect to gender and age [23].

In the NIVEL-PCD, GPs record information on the diagnosis and prescriptions of each consultation. Diagnoses are recorded using the International Classification of Primary Care 1 (ICPC-1) codes [24]. Prescriptions are recorded using Anatomical Therapeutic Chemical Classification System (ATC) codes [25].

The medical records were matched to individual records in the Dutch population registry using a unique anonymous patients' identifier (based on gender, date of birth, and postal code). The degree of urbanization of the patients' residence (five categories, based on population density per postal code area), obtained from Statistics Netherlands, was also linked to the database [26]. Both NIVEL and Statistics Netherlands, responsible for the management of the population registry, approved this study. Using the data in this manner and for this purpose is permitted under Dutch law and no additional ethical approval is needed.

\section{Study population}

We included all 15-to 60-year-old patients registered at the participating GPs in the NIVEL-PCD during the study period 2002 to 2011 who could be identified in the population registry.

\section{STI-related episodes}

For episode-based registration, multiple consultations concerning one health problem were grouped into disease episodes as registered by the GP or as constructed by the validated application EPICON, that groups consultations with similar ICPC-codes occurring less than two months apart [27]. An STI-related episode was defined as an episode with an ICPC code for a positive STI-diagnosis or an episode with the ICPC code for fear of STI or HIV/AIDS (Table 1). GPs register the latter codes in case of a consultation where STI-related questions were discussed and/or an STI test was done, but no STI was diagnosed. Because there is no ICPC code for chlamydia, we combined prescription data with specific ICPC codes to define a chlamydia episode (Table 1) $[3,21]$. There were probably more episodes during which STI-related issues were discussed or STI-tests were performed, but we used only the final ICPC code assigned to each episode. Patients can have multiple STI-related episodes per year. Hepatitis B and C are not included in this study, since there are no specific ICPC-1 
Table 1 Definition of STI-related episode

\begin{tabular}{lll}
\hline STI-related episode & $\begin{array}{l}\text { Men } \\
\text { ICPC-1 code }\end{array}$ & $\begin{array}{l}\text { Women } \\
\text { ICPC-1 code }\end{array}$ \\
\hline Fear for STI or HIV/AIDS & & \\
Fear of STI & B25 & B25 \\
Fear of HIV/AIDS & Y25 & X23 \\
STI-diagnosis & & \\
HIV infection/AIDS & B90 & B90 \\
Syphilis & Y70 & X70 \\
Gonorrhea & Y71 & X71 \\
Trichomoniasis & Not included & X73 \\
Herpes genitalis & Y72 & X90 \\
Genital warts & Y76 & X91 \\
Non-specific urethritis & U72 & Not included \\
Chlamydia & & \\
- Orchitis/Epididymitis & & \\
- Other genital disease & Y74 & \\
- Pelvic inflammatory disease & & Y99 \\
- Vaginitis & & $X 85$ \\
- Cervicitis & &
\end{tabular}

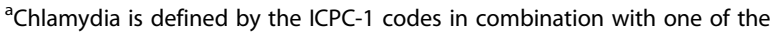
following ATC prescription codes: J01FA10, J01AA02, J01FA01, J01MA01, J01MA02, J01CA04 (for women only)

codes for these infections. There is a code for hepatitis in general, but this also includes other infections.

\section{Ethnicity}

We used (parental) country of birth, as recorded in the population registry, to define the ethnicity of patients and the generation of EM (Fig. 1) [28]. Patients with at least one parent born abroad are considered EM. Firstgeneration EM are themselves also born abroad, and second-generation EM are themselves born in the Netherlands. Patients with both parents born in the Netherlands are considered native Dutch. In this study, we focused on ethnicities that were most prevalent among the 15-to 60-year-old Dutch population in 2002 to 2011: native Dutch (79.3 \%), Moroccan (1.9\%), Turkish (2.3\%), Surinamese (2.3\%), Antillean/Aruban (0.9\%). Other ethnicities were classified as Western (8.5\%) or non-Western (4.8\%) [29].

\section{Statistical analyses}

Per ethnic group, we calculated the proportion of all registered episodes that were STI-related. In order to compare STI consultations at the GP between ethnic groups, the reporting rate of STI-related episodes was calculated per ethnic group as the number of STI-related episodes per 100,000 patient years (PYs). Gender differences were analyzed as well as trends over time using chi-square for trend.

We performed uni-and multivariable logistic regression analyses on the outcome STI-related episodes to investigate the difference between EM and native Dutch. Analyses were adjusted for gender, age and degree of urbanization. We performed the logistic regression analyses on the data of 2011 only, because this represents the most recent situation. A p-value less than 0.05 was considered statistically significant. Analyses were performed using SPSS version 20.

\section{Results}

\section{Study population}

The number of participating GPs in the NIVEL-PCD, and consequently the number of registered patients, fluctuated

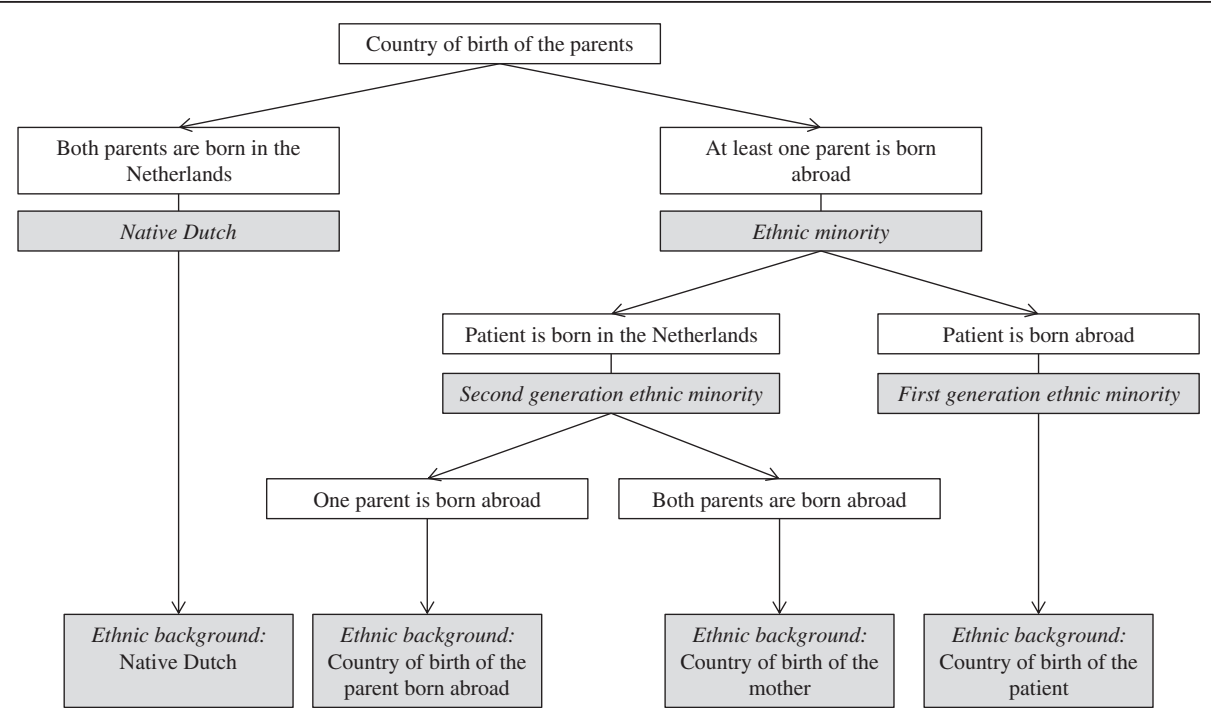

Fig 1 Flowchart to determine ethnic background 
each year. The mean number of registered 15-to 60-yearold patients was 383,712 per year [range: 289,804$475,122]$ which is about $2.5 \%$ of the total Dutch 15 -to 60-year-old population [29].

Of all 15-to 60-year-old registered patients, $66.8 \%$ could be identified in the population registry. Of the patients who consulted the GP, $88.4 \%$ could be identified. Reasons for the inability to identify patients were for example an unknown date of birth or (recent) change of address. Identified patients were somewhat older; of the 45-to 60-year-old patients, $71.6 \%$ could be identified compared with $61.3 \%$ of the 25 - to 34-year-old patients.

Of the study population $80.8 \%$ was native Dutch, $1.7 \%$ Moroccan, $2.0 \%$ Turkish, $2.1 \%$ Surinamese and $0.9 \%$ was Antillean/Aruban. The majority of the EM were first-generation EM (59.3 \%). Characteristics of the study population are presented in Additional file 1.

\section{STI-related episodes by ethnicity}

Between 2002 and 2011 a total of 3,749,370 episodes were registered, of which 21,065 (0.6 \%) were STI-related. The percentage of episodes registered as STI-related differed by ethnicity and generation of EM (Table 2). The highest percentage was observed among Antillean/Aruban EM; of all registered episodes $2.0 \%$ was STI-related. The lowest percentages were observed among Turkish EM (0.4 \%) and native Dutch (0.5\%).

The overall reporting rate of STI-related episodes at the GP increased from 479 per 100,000 PY in 2002 to 1,240 per 100,000 PY in 2011. Among some ethnic groups the reporting rate first declined from 2002 until 2004 followed by an increase (Fig. 2). The increasing trend from 2004 onwards was significant across all ethnic groups and generations of EM ( $\mathrm{p}<0.001)$. Antillean/Aruban and Surinamese EM had more often an STI-related episode at the GP than other ethnic groups during the entire study period (Fig. 2a) and second-generation EM more often than first-generation EM (Fig. 2b). Except for Moroccan, Turkish, other non-Western EM and first-generation EM, women had a higher reporting rate of STI-related episodes than men (Fig. 3).

The reporting rate of a positive STI-diagnosis was the highest among Antillean/Aruban and Surinamese EM, in line with the higher rate of STI-related episodes. The ratio of STI-diagnoses to all STI-related episodes differed between ethnic groups. Among Moroccan men and firstgeneration EM men, proportionally more positive STIdiagnoses were registered during STI-related episodes than among other ethnic groups, for example native Dutch and Antillean/Aruban women. In general, the episodes registered as STI-related less often included a positive STI-diagnosis among women than among men of the same ethnicity, except for Turkish EM (Fig. 3).

Univariable logistic regression analyses showed that, in 2011, all EM (both first and second generation) had more often an STI-related episode than native Dutch, except for Turkish EM in which results were similar to native Dutch (Table 3). Adjustment for gender did not affect these results. Further adjustment for age did attenuate but not remove the associations. Only for Turkish EM adjustment for age resulted in less STIrelated episodes compared with native Dutch. After additional adjustment for degree of urbanization, there were no differences between Moroccan or other non-Western EM and native Dutch, and between first-generation EM and native Dutch. Differences in demographic characteristics between ethnic groups are presented in the Additional file 2.

Table 2 Number of episodes per patient year and the proportion of episodes that was STI-related. In the period 2002 to 2011 , by ethnicity and generation of ethnic minorities (EM)

\begin{tabular}{|c|c|c|c|c|c|}
\hline & Patient years & Number of episodes & $\begin{array}{l}\text { Number of episodes per } \\
\text { patient year [95\% Cl] }\end{array}$ & $\begin{array}{l}\text { Number of STI-related } \\
\text { episodes }\end{array}$ & $\begin{array}{l}\% \text { STI-related episodes } \\
\text { of all episodes [95 \% CI] }\end{array}$ \\
\hline Total & $2,563,599$ & $3,749,370$ & $1.46[1.46-1.46]$ & 21,065 & $0.56[0.55-0.57]$ \\
\hline \multicolumn{6}{|l|}{ Ethnicity } \\
\hline Native Dutch & $2,071,677$ & $2,970,801$ & $1.43[1.43-1.44]$ & 14,976 & $0.50[0.50-0.51]$ \\
\hline Moroccan & 42,965 & 76,737 & $1.79[1.77-1.80]$ & 524 & $0.68[0.63-0.74]$ \\
\hline Turkish & 52,051 & 100,473 & $1.93[1.92-1.94]$ & 446 & $0.44[0.40-0.49]$ \\
\hline Surinamese & 53,212 & 98,033 & $1.84[1.83-1.85]$ & 1,098 & $1.12[1.06-1.19]$ \\
\hline Antillean, Aruban & 23,570 & 35,303 & $1.50[1.48-1.51]$ & 714 & $2.02[1.88-2.17]$ \\
\hline Non-western, other & 97,887 & 149,218 & $1.52[1.52-1.53]$ & 1,233 & $0.83[0.78-0.87]$ \\
\hline Western, other & 222,237 & 318,805 & $1.43[1.43-1.44]$ & 2,074 & $0.65[0.62-0.68]$ \\
\hline \multicolumn{6}{|l|}{ Generation of EM } \\
\hline $1^{\text {st }}$ generation & 291,911 & 491,214 & $1.68[1.68-1.69]$ & 3,121 & $0.64[0.61-0.66]$ \\
\hline $2^{\text {nd }}$ generation & 200,011 & 287,355 & $1.44[1.43-1.44]$ & 2,968 & $1.03[1.00-1.07]$ \\
\hline
\end{tabular}




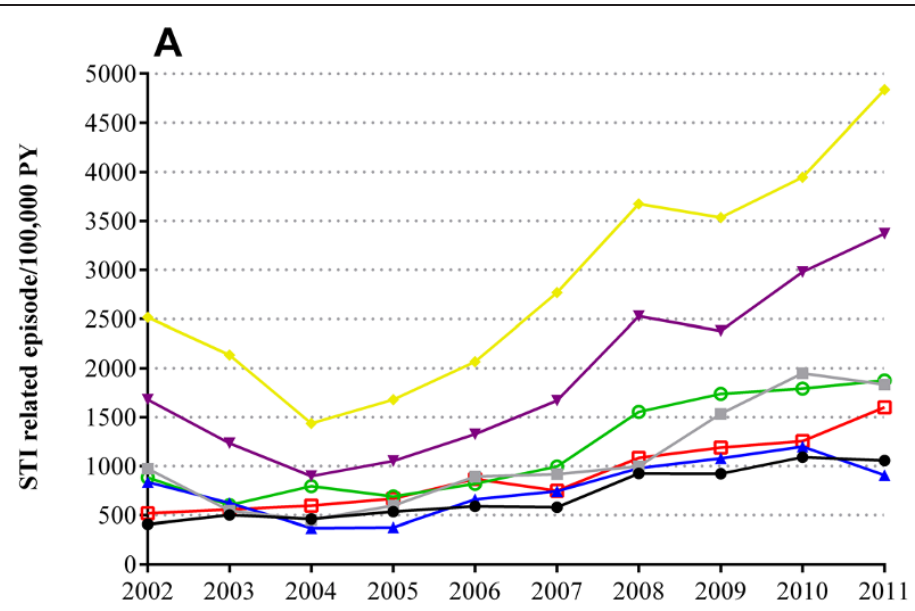

$\rightarrow$ Native Dutch

-- Moroccan

- Turkish

+ Surinamese

$\rightarrow$ Antillean, Aruban

$\neg$ Non-Western, other

七 Western, other

B

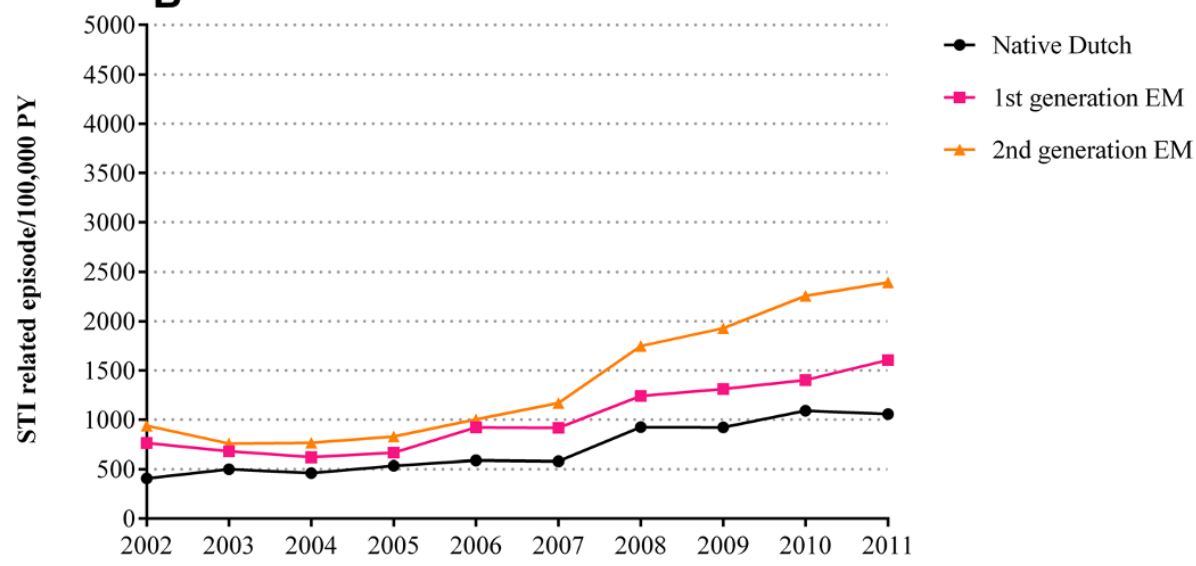

Fig 2 Reporting rate of STI-related episodes per year (2002 to 2011). a) Reporting rate of STI-related episodes by ethnicity. b) Reporting rate of STI-related episodes by generation of ethnic minorities (EM)

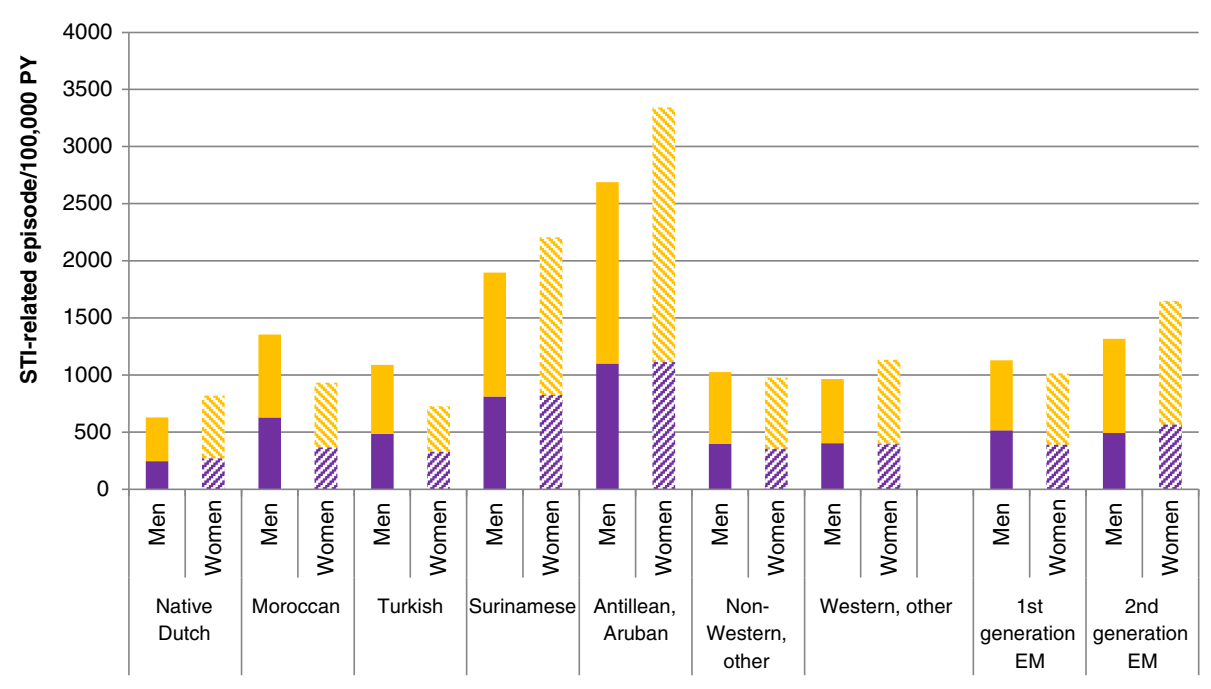

- STI diagnoses $\square$ Fear of STI or HIV/AIDS

Fig. 3 Reporting rate of STI-related episodes divided into STI diagnoses and fear of STI or HIV/AIDS. In the period 2002 to 2011, by ethnicity, generation of ethnic minorities (EM), and gender 
Table 3 Crude and adjusted Odds Ratio for STI-related episodes by ethnicity and generation of ethnic minorities. Adjusted for gender, age and degree of urbanization, using data from 2011

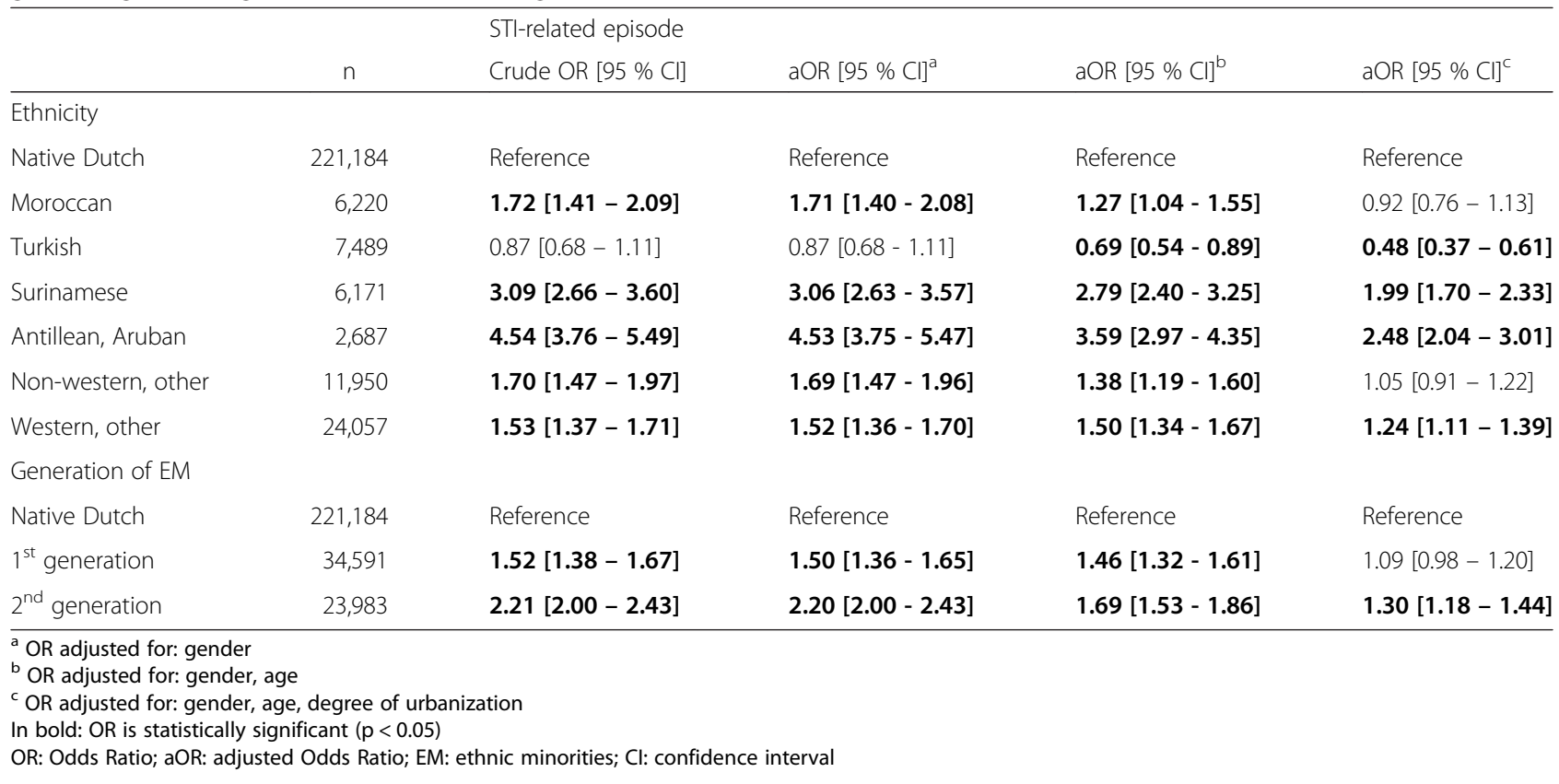

\section{Discussion}

At general practices in the Netherlands, EM consult the GP more often for STI care than native Dutch, except for Turkish EM. A lower age and a higher degree of urbanization explained the higher consultation rate among Moroccan and non-Western EM, but not among Antillean/Aruban, Surinamese and other Western EM. In addition, the percentage of episodes that was STIrelated was higher for EM (except for Turkish EM) than for native Dutch.

\section{Strengths and limitations}

A strength of our study is that we were able to match the majority of the patients registered in a large nationally representative general practice database with the population register, which made it possible to determine the patients' ethnicity, since this is not registered in the general practice data [23].

A limitation was that $33 \%$ of the patients registered in the NIVEL-PCD could not be identified in the population registry, which could have led to selection bias. However, the distribution of EM in the study population was comparable with the total Dutch population [29]. We have no reason to assume that possible selection bias is related to STI-related episodes.

Furthermore, episodes, like vaginitis or vaginal discharge, in which an STI test was performed but with a "non-STI" final diagnosis, do not appear as an STIrelated episode in our study, leading to an underestimation of all episodes involving an STI test and to a relatively high proportion of STI-related episodes where an STI was diagnosed. This makes a comparison with the STI positivity rate, for example reported by STI clinics [2], impossible.

Finally, since we did not have information on sexual risk behavior and underlying need for an STI consultation, we could not draw any conclusions on the adequacy of STI care by GPs.

\section{Discussion of findings}

Our findings differ from earlier findings from Trienekens et al. who suggested that EM consult the GP less frequently for STI care than native Dutch [20]. They compared the proportion of EM among people who consulted the GP for STI care (16\%, based on self-defined ethnicity) with the proportion of EM in the overall Dutch population (20\%, based on (parental) country of birth). Since selfdefined ethnicity often leads to an underestimation of EM [11], this could explain the difference with our results (in our data $29 \%$ of STI-related episodes was among EM). Van Bergen et al. showed that EM consult their GP more often after experiencing STI-related symptoms than native Dutch, which is in line with our results [17].

Comparing our data to data from STI centers, it seems that Turkish, Moroccan and Antillean/Aruban EM may prefer to consult the GP to the STI center for STI care. In 2011, $1.3 \%$ of the visitors at the STI center was Turkish compared with $2.0 \%$ of the patients with an STI-related episode at the GP. For Moroccan EM these percentages were $1.8 \%$ at the STI center and $3.3 \%$ at the GP, and for Antillean/Aruban EM $2.8 \%$ and $3.7 \%$ respectively [30]. Comparable data from other countries 
is limited since the regulation of STI care differs widely between countries. In the UK, the ethnicity of women diagnosed with chlamydia in primary care did not differ from those diagnosed in genitourinary medicine clinics [31]. In the US, men attending a public STI clinic were more often black compared to men attending a nonpublic clinic [32].

Especially Antillean/Aruban and Surinamese EM consulted the GP relatively often for STI care compared with native Dutch. This is in line with previous Dutch research showing a high proportion of these ethnic groups with a previous/recent STI/HIV test $[16,33]$. Also in the UK, Black Caribbeans reported more frequently a genitourinary medicine clinic visit and a previous HIV test than white ethnic groups [5].

It seems that Antillean/Aruban and Surinamese EM find their way to STI care, while their STI prevalence remains high. The odds of being diagnosed with a single STI at the STI center was about 1.5 times higher among Antillean/ Aruban or Surinamese EM than among native Dutch, and the odds of a co-infection was 3.6-5.9 times higher [16]. In a Dutch screening program, the odds of being diagnosed with chlamydia was 3.0-4.3 times higher among Antillean/ Aruban or Surinamese EM than among native Dutch [11]. In our study, the odds of having an STI-related episode at the GP was 2.0-2.5 times higher among Antillean/Aruban or Surinamese EM than among native Dutch. Although the higher STI consultation rate at the GP among Antillean/ Aruban and Surinamese EM is reassuring, we are not certain that this covers their higher need.

In our study, there was no difference in the STI consultation rate between Moroccan EM and native Dutch (after adjustment for gender, age and degree of urbanization), while Turkish EM had a lower consultation rate. For Moroccan and Turkish EM it is debatable whether they are at higher STI risk than native Dutch. At the STI center, Moroccan or Turkish women had a 1.2 higher odds of being diagnosed with a single STI than native Dutch women, and a 2.2 higher odds of having a co-infection, while there was no increased risk among Moroccan or Turkish men [16]. The chlamydia positivity rate in a screening program was higher for Moroccan EM than for native Dutch (OR: 1.9) while there was no difference between Turkish EM and native Dutch (OR: 1.0) [11]. It is uncertain whether this is a reflection of the general Moroccan and Turkish population, since only a selective group will come forward to get tested.

In contrast to other ethnic groups, Moroccan and Turkish women consulted the GP less often for STI care than men. This may be culturally related since Islamic women are expected to keep their virginity until marriage [34]. A Belgium study showed that Moroccan women are less concerned about safe sex, as they do not have sex before marriage. However, premarital sex seems to be acceptable for Moroccan men [35]. Also in the Netherlands young Islamic women find that remaining a virgin until marriage is stricter for women than for men [36]. Indeed, Moroccan and Turkish women seem to have lower sexual risk behavior (less sexual experience at young age and less sexual partners) than native Dutch women, although their condom use is lower. Moroccan and Turkish men seem to have higher sexual risk behavior than native Dutch men (more sexual experience at young age, more sexual partners, more often commercial sex) $[18,33,35,37]$.

Currently, the ethnic background of patients is often not registered in general practices in the Netherlands. Nevertheless, ethnic background is an important determinant for many diseases, including STIs. Although some are concerned it may be perceived as stigmatizing, including ethnicity in patient registers and surveillance data will give more insight into the influence of ethnicity on patients' health and use of primary health care and would enable a more focused approach regarding service provision, education and further research in the care of this important patient group within primary care [22].

\section{Conclusion}

In conclusion, EM consult their GP more often for STIs than native Dutch, but it is unknown whether this covers the need of EM groups at higher STI risk. The GP has an important role in STI care, especially in EM groups; it is therefore imperative that GPs use the opportunity of an STI-consultation (or other chances) to offer the complete STI-test package (including HIV), following the rules from the recently renewed guideline for STI consultations at the general practice [38].

\section{Additional files}

Additional file 1: Characteristics of the study population per year (2002 to 2011).

Additional file 2: Characteristics of the study population in 2011, by ethnicity and generation of ethnic minorities (EM).

\section{Abbreviations}

aOR: Adjusted Odds Ratio; ATC: Anatomical Therapeutic Chemical Classification System; Cl: Confidence interval; EM: Ethnic minorities; GP: General practitioners; ICPC: International Classification of Primary Care; NIVEL: Netherlands Institute for Health Sciences Research; NIVEL-PCD: NIVEL Primary Care Database; OR: Odds Ratio; PY: Patient year; STI: Sexually transmitted infection.

\section{Competing interests}

The authors declare that they have no competing interests.

\section{Authors' contributions}

PW was involved in analyzing and interpreting the data and drafted the manuscript. AO helped interpreting the data and revised the manuscript. IS was involved in the management of the NIVEL-PCD database and advised and commented on earlier versions on the manuscript. BB and JB revised and corrected the draft. IB initiated and designed the study and revised the manuscript. All authors read and approved the final manuscript. 


\section{Acknowledgments}

The authors would like to thank all GPs participating in the NIVEL-PCD for registering their consultations and Statistics Netherlands for the possibility to link the population registry and the NIVEL-PCD database.

\section{Author details}

${ }^{1}$ Centre for Infectious Disease Control, National Institute for Public Health and the Environment (RIVM), Bilthoven, The Netherlands. ${ }^{2}$ Netherlands Institute for Health Services Research (NIVEL), Utrecht, The Netherlands. ${ }^{3}$ STI AIDS Netherlands, Amsterdam, The Netherlands. ${ }^{4}$ Department of General Practice, Academic Medical Center, Amsterdam, The Netherlands.

\section{Received: 30 January 2015 Accepted: 18 May 2015}

\section{Published online: 18 June 2015}

\section{References}

1. Coenen AJ, Berends R, Van der Meijden WI. The organization of STI control in the Netherlands-an overview. Int J STD AIDS. 2002;13(4):254-60.

2. van Aar F, Koedijk FDH, Van den Broek IVF, Op de Coul EL, Soetens LC, Woestenberg PJ, et al. Sexually Transmitted Infections Including HIV, in the Netherlands in 2013. Bilthoven: National Institute for Public Health and the Environment; 2014.

3. van den Broek IV, Verheij RA, van Dijk CE, Koedijk FD, van der Sande MA, van Bergen JE. Trends in sexually transmitted infections in the Netherlands, combining surveillance data from general practices and sexually transmitted infection centers. BMC Fam Pract. 2010;11:39

4. Van Veen M, Van der Sande M, David S, Koedijk F. Aanvullende regeling Seksuele Gezondheidszorg (ASG) - Betere aansluiting preventie en behandeling. [Additional arrangement sexual healthcare (ASG) - Better connection between prevention and cure]. Seksoa. 2012;3(1):8-9.

5. Fenton KA, Mercer CH, McManus S, Erens B, Wellings K, Macdowall W, et al. Ethnic variations in sexual behaviour in Great Britain and risk of sexually transmitted infections: a probability survey. Lancet. 2005;365(9466):1246-55.

6. Laumann EO, Youm Y. Racial/ethnic group differences in the prevalence of sexually transmitted diseases in the United States: a network explanation. Sex Transm Dis. 1999;26(5):250-61.

7. Low N, Sterne JA, Barlow D. Inequalities in rates of gonorrhoea and chlamydia between black ethnic groups in south east London: cross sectional study. Sex Transm Infect. 2001;77(1):15-20.

8. James $A B$, Geisler WM. Predictors of high chlamydia and gonorrhea positivity rates among men in the southern United States. J Natl Med Assoc. 2012;104(1-2):20-7.

9. Sinka K, Mortimer J, Evans B, Morgan D. Impact of the HIV epidemic in subSaharan Africa on the pattern of HIV in the UK. Aids. 2003;17(11):1683-90.

10. Del Amo J, Likatavicius G, Perez-Cachafeiro S, Hernando V, Gonzalez C, Jarrin I, et al. The epidemiology of HIV and AIDS reports in migrants in the 27 European Union countries, Norway and Iceland: 1999-2006. Eur J Public Health. 2011;21(5):620-6.

11. Haasnoot A, Koedijk FD, Op De Coul EL, Gotz HM, van der Sande MA, Van Den Broek IV, et al. Comparing two definitions of ethnicity for identifying young persons at risk for chlamydia. Epidemiol Infect. 2012;140(5):951-8.

12. van den Broek IV, van Bergen JE, Brouwers EE, Fennema JS, Gotz HM, Hoebe CJ, et al. Effectiveness of yearly, register based screening for chlamydia in the Netherlands: controlled trial with randomised stepped wedge implementation. BMJ. 2012;345:e4316.

13. Gotz HM, van Bergen JE, Veldhuijzen IK, Broer J, Hoebe CJ, Steyerberg EW, et al. A prediction rule for selective screening of Chlamydia trachomatis infection. Sex Transm Infect. 2005;81(1):24-30.

14. Op de Coul EL, Gotz HM, van Bergen JE, Fennema JS, Hoebe CJ, Koekenbier RH, et al. Who participates in the Dutch Chlamydia screening? A study on demographic and behavioral correlates of participation and positivity. Sex Transm Dis. 2012:39(2):97-103.

15. van Bergen J, Gotz HM, Richardus JH, Hoebe CJ, Broer J, Coenen AJ, et al. Prevalence of urogenital Chlamydia trachomatis increases significantly with level of urbanisation and suggests targeted screening approaches: results from the first national population based study in the Netherlands. Sex Transm Infect. 2005;81(1):17-23.

16. de Coul EL, Warning TD, Koedijk FD, Dutch STI. Sexual behaviour and sexually transmitted infections in sexually transmitted infection clinic attendees in the Netherlands, 2007-2011. Int J STD AIDS. 2014;25(1):40-51.

17. van Bergen JE, Kerssens JJ, Schellevis FG, Sandfort TG, Coenen TT, Bindels PJ. Sexually transmitted infection health-care seeking behaviour in the Netherlands: general practitioner attends to the majority of sexually transmitted infection consultations. Int J STD AIDS. 2007;18(6):374-9.

18. de Graaf H, Kruijer H, van Acker J, Meijer M. Seks onder je 25e. [Sex under 25 years of age]. Utrecht: Rutgers WPF, Soa aids Nederland; 2012.

19. David S. Nationaal soa/hiv-plan 2012-2016. [national policy plan STI/HIV 20122016]. Bilthoven: National Institute for Public Health and the Environment; 2011.

20. Trienekens SC, van den Broek IV, Donker GA, van Bergen JE, van der Sande MA. Consultations for sexually transmitted infections in the general practice in the Netherlands: an opportunity to improve STI/HIV testing. BMJ Open. 2013;3(12), e003687.

21. Suijkerbuijk AW, van den Broek IV, Brouwer HJ, Vanrolleghem AM, Joosten JH, Verheij RA, et al. Usefulness of primary care electronic networks to assess the incidence of chlamydia, diagnosed by general practitioners. BMC Fam Pract. 2011;12:72.

22. Essink-Bot ML, Stronks K. Verantwoorde zorg vereist registratie van etnische herkomst. [Responsible care requires registration of ethnic origin]. Ned Tijdschr Geneeskd. 2009;153:A337.

23. Landelijk Informatienetwerk Huiartsenzorg (LINH). Cijfers-AandoeningenIncidentie en Prevalentie cijfers. [Morbidity-Incidence and Prevalence rates] [http://www.linh.nl]. Accessed 17 Dec 2013

24. Lamberts $\mathrm{H}$, Wood M. The birth of the International Classification of Primary Care (ICPC). Serendipity at the border of Lac Leman. Fam Pract. 2002;19(5):433-5.

25. WHO Collaborating Centre for Drug Statistics Methodology. Guidelines for ATC classification and DDD assignment 2014. Oslo: WHO Collaborating Centre for Drug Statistics Methodology; 2013.

26. Statistics Netherlands. Gebieden in Nederland [Areas in the Netherlands]. [http://statline.cbs.nl/Statweb]. Accessed 21 Oct 2014

27. Biermans MC, Elbers GH, Verheij RA, van der Jan Veen W, Zielhuis GA, Robbe PF. External validation of EPICON: a grouping system for estimating morbidity rates using electronic medical records. J Am Med Inform Assoc. 2008;15(6):770-5.

28. Stronks K, Kulu-Glasgow I, Agyemang C. The utility of 'country of birth' for the classification of ethnic groups in health research: the Dutch experience. Ethn Health. 2009;14(3):255-69.

29. Statistics Netherlands. Bevolking; generatie, geslacht, leeftijd en herkomstgroepering, 1 januari. [Population; generation, gender, age and origin, 1 Januari] [http://statline.cbs.nl/StatWeb/]. Accessed 21 Oct 2013

30. Trienekens SCM, Koedijk FDH, Van den Broek IVF, Vriend HJ, Op de Coul EL, Van Veen MG, et al. Sexually Transmitted Infections Including HIV, in the Netherlands in 2011. Bilthoven: National Institute for Public Health and the Environment; 2012.

31. Cassell JA, Mercer CH, Fenton KA, Copas AJ, Erens B, Wellings K, et al. A comparison of the population diagnosed with chlamydia in primary care with that diagnosed in sexual health clinics: implications for a national screening programme. Public Health. 2006;120(10):984-8.

32. Porter CA, Thompson D, Erbelding EJ. Differences in demographics and risk factors among men attending public $v$ non-public STD clinics in Baltimore, Maryland. Sex Transm Infect. 2004;80(6):488-91.

33. Goenee $\mathrm{M}$, Kedde $\mathrm{H}$, Picavet $\mathrm{C}$. Condoomgebruik en testgedrag in Nederland. [Condom use and testing behaviour in the Netherlands] Tijdschrift voor Seksuologie. 2012;36(2):109-20.

34. Kadri N, Mchichi Alami K, Berrada S. Sexuality in Morocco: Women sexologist's point of view. Sexologies. 2010;19:20-3.

35. Hendrickx K, Lodewijckx E, Van Royen P, Denekens J. Sexual behaviour of second generation Moroccan immigrants balancing between traditional attitudes and safe sex. Patient Educ Couns. 2002;47(2):89-94.

36. Cense M. Laveren tussen autonomie en loyaliteit, allochtone jongeren over seksualiteit en liefde. [Navigate between autonomy and loyalty, immigrant youth about sexuality and love]. [https://www.soaaids.nl/nl/laveren-tussenautonomie-en-loyaliteit]. Accessed 21 Oct 2013.

37. De Graaf H. Seksueel gedrag en seksuele beleving in Nederland. [Sexual behaviour and sexual experience in the Netherlands]. Tijdschrift voor Seksuologie. 2012;36(2):87-97.

38. Van Bergen J, Dekker J, Boeke J, Kronenberg E, van der Spruit R, Burgers J, et al. NHG-Standaard Het soa-consult (eerste herziening). [NHG-guidline STI consultation (second edition)]. Utrecht: Nederlands Huisartsen Genootschap $(\mathrm{NHG}) ; 2013$. 